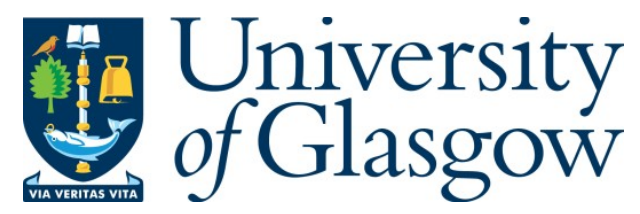

Shaffer, M. and Stewart, E. (2021) Refugees on the move: resettlement and onward migration in 'final' destination countries. In: Cohen, J. H. and Sirkeci, I. (eds.) Handbook of Culture and Migration. Series: Elgar Handbooks in Migration. Edward Elgar, pp. 341-350. ISBN 9781789903454

(doi: $10.4337 / 9781789903461.00037)$

This is a draft chapter. The final version is available in Handbook of Culture and Migration edited by Cohen, J. H. and Sirkeci, I. published in 2021, Edward Elgar Publishing Ltd (doi: $10.4337 / 9781789903461.00037)$

The material cannot be used for any other purpose without further permission of the publisher, and is for private use only.

https://eprints.gla.ac.uk/235569/

Deposited on: 2 March 2021

Enlighten - Research publications by members of the University of Glasgow http://eprints.gla.ac.uk 
This is a draft chapter. The final version is available in the Handbook of Culture and Migration edited by Cohen, J.H and Sirkeci, I, published in 2021, Edward Elgar Publishing Ltd

DOI: https://doi.org/10.4337/9781789903461.00037

The material cannot be used for any other purpose without further permission of the publisher, and is for private use only.

\title{
Refugees on the Move: Resettlement and Onward Migration in 'Final' Destination Countries
}

\begin{abstract}
Refugee migration is often discussed in isolation from other types of mobility. Refugee movement is distinguished by the perception that such migrations are forced and occur among disempowered individuals and populations lacking autonomy. This essay dispels the notion that refugees are not involved in making decisions about their mobility. We situate refugee migration as one category of movement, and then discuss migration trajectories and how individuals determine where they will go and how they will get there. Finally, we discuss refugee resettlement and onward migration, exploring why resettlement does not necessarily stop movement. Many refugees continue to migrate even after resettlement as they search for jobs, co-ethnic communities, a sense of belonging, and so on, which contradicts the policy goals of creating a permanent home in a new country.
\end{abstract}

Keywords: refugees, resettlement, dispersal, onward migration, integration, UK, South Africa

Refugees present a unique challenge for academics conducting migration studies, for practitioners providing services, and for politicians developing policies to serve this population. Refugees are often depicted as a unitary category of movers who, because of their victimhood, lack autonomy and survive through the generosity of rich countries or any host in a location where refugees find themselves living (Cabot, 2016; Crawley \& Skleparis, 2018; Johnson, 2011; Ongenaert \& Joye, 2019; Zetter, 2007). Refugees are portrayed as a problem in need of a solution. Refugees are a global humanitarian obligation that many countries, in today's anti-immigration climate, do not want to be responsible for. Countries that accept refugees feel pinched by space and the resources required to absorb these populations. Many of these countries' leaders and citizens increasingly support distributing the burden of refugee resettlement more equitably among nation-states, though there is little agreement over how many refugees this should include. Resettlement implies a permanent solution to a person's insecurity 
and to a refugee's mobility. The goal of resettlement is to stop movement in search of a secure home. Resettlement is supposed to demonstrate a host's investment in an individual as part of a country's duty to the global community and as a United Nations signatory, with the expectation that in return the individual will cease to move and instead invest in his or her adopted community.

Angst surrounding refugee resettlement and migration generally has proliferated with the rise of nationalism in recent years. It continues to pose a significant threat to the lives and livelihoods of not only refugees but also to those already living in resettlement countries. Shifting attitudes toward refugees, especially those coming from Islamic countries, have reduced Western appetites for resettlement and other migration schemes that benefit individuals from poor or violence-torn societies. For example, the United States admitted nearly 85,000 refugees in fiscal year 2016, the final year of Barack Obama's presidency. Under the Trump administration's policy to ban migrants from countries with some of the world's greatest humanitarian needs, resettlement numbers have decreased. A total of 53,691 refugees were admitted to the US for resettlement during 2017 (Office of Immigration Statistics, 2019), Trump's first year in office, while 2019 was capped at no more than 30,000 individuals. To put this in a global context, there were just under 71 million forcibly displaced persons worldwide in 2018, nearly 26 million of whom were refugees. The United Nations High Commissioner for Refugees (UNHCR) reports that 92,400 refugees were resettled to 25 countries in 2018. The US absorbed 22,900 of those individuals (UNHCR, 2019b). As current US policy tightens its reins and continues to limit new refugees entering the country, global resettlement numbers have plummeted. This decline has a profound impact on the lives of those already resettled in the US. Many refugees live without their spouses, children, and the daily partnership as well as support of their loved ones who are unable to travel for reunification. These outcomes are the direct result of policies that will continue to keep families separated. The US will admit up to 18,000 refugees during fiscal year 2020 (White House, 2019), which will only exacerbate the problem.

With the advent of the European Union (EU) 'refugee crisis' in 2015, member states were faced with the challenge of significant refugee flows seeking protection and settlement at the gates of Fortress Europe. Except for Germany, a country that accepted nearly one million refugees, the response across Europe was lukewarm at best and sometimes uncaringly aggressive, particularly among border states such as Hungary. More recently, Syrian refugees trying to enter Greece from Turkey have been met with violence and hostility. The desire to control national borders and limit the number of immigrants and refugees entering the country also played an important role in the UK's decision to leave the EU. Indeed, 
parts of the UK Brexit campaign focused on the fear of 'others' and promoted an exclusionary politics of identity as a means to endorse separation from the EU. The resettlement of refugee populations continues to be politicized in the EU context. The Turkish President, Recep Tayyip Erdogan, has threatened to 'flood' Europe by opening the doors and sending 3.7 million refugees to the continent in response to EU member states critiquing Turkish military action in Syria. The politically charged issue of refugees and their resettlement plays into emotionally charged views of nationalism, racism, xenophobia, exceptionalism, culture, identity, economics, and the rising fear of globalization's impact.

Security, and its existence at multiple scales, is crucial to understanding these issues. Governments use 'security' as a justification for denying refugee resettlement, implying refugees are national security threats to societies and their presence may lead to violence. At the local level, refugees, like other migrants, are perceived as economic threats who 'steal' jobs from citizens and deplete the social resources that are provided by the state to its naturally born citizens. And within some communities, refugees increasingly are discussed as cultural threats, bringing rituals, practices, and belief systems with them that threaten the continuity of a host country's cultural core. The unfounded belief that refugees refuse to integrate into their adopted communities typically leads to host societies feeling threatened (Esses, Medianu \& Lawson 2013; Murray \& Marx, 2013). Apprehension is tied to perceptions of social, cultural, environmental, and economic insecurity that citizens feel when refugees arrive at their doorstep. For example, the face of neighborhoods changes as immigrant populations assert their presence by building their communities (Robinson, 2010), such as through the establishment of ethnic food stores, restaurants, or places of worship. Countries that host large numbers of refugees and migrants generally - especially those movers who are culturally dissimilar to their adopted home in significant ways - feel increasingly insecure about the presence of foreigners and the impact they will have on society.

Migration discourse often paints refugees with a broad brush, neglecting the critical importance of culture, context, and the nuances that shape human mobility. Decisions, even in forced migration, are influenced or determined by gender, age, health, religion, families, households, and other structural factors (Betts, 2013; FitzGerald \& Arar, 2018). Luck, opportunity, economics, politics, and geography also play their part. Collectively, who moves, where they go, and how they get there are parts of an incredibly complex web of actors and circumstances working in tandem to shape migration outcomes. Refugees' willingness to move and reasons for migrating can be understood not only by these practical explanations, but also by the central role culture plays in conceptualizing movement and realizing 
resettlement. For example, Somalis generally attribute their propensity to move on their nomadic heritage, suggesting they emanate from a culture of migration (Cohen \& Sirkeci, 2011). Migration is tied to identity; it is part and parcel of what it means to be a Somali. The spirit of migration was wellestablished long before the Somali state collapsed in 1991 and pushed millions of Somalis into the diaspora. This connection to migration continues to inspire mobility among those who left the country and resettled elsewhere decades ago.

Refugee movement is a fluid process that does not end after leaving home and the homeland. For most refugees, migration is a continuous process that takes individuals, families, and households to new destinations that may not have been part of a planned journey. Traversing the realities of smuggling routes and frustrated by strict (and often fluctuating) border controls and restrictions, the search for a new home can lead to years-long movement through countries or across continents, considering multiple options and strategizing various routes to reach new destinations. Refugees often draw on social or kinship networks to make decisions about where to go and how to access opportunities that facilitate movement. The act of moving is guided using networks and existing knowledge about migration journeys (Shaffer, Ferrato \& Jinnah, 2018). Consequently, what is perceived as destination countries, such as those in Europe or the US where asylum cases are granted or refugee status has been obtained, sometimes do not lead to permanent resettlement.

This essay seeks to accomplish several goals. First, we present refugees as sharing their migration objectives with other categories of movers. Second, we discuss refugee migration trajectories and how movers determine and arrive at their planned destinations. Finally, we discuss the issue of permanence and what it means to be resettled in a final destination country and in order to challenge the sedentary bias inherent in refugee resettlement policies. To do so, we explore the issue of culture and migration through the lens of internal migration in developed (UK) and less developed (South Africa) contexts. We integrate discussions of culture throughout the chapter and show that migration decisions are grounded in the family and engage households as well as communities. We consider not only the cultural context of ethnic movers and their motivations to move on or stay, but also the ways in which receiving societies - cities and neighborhoods - perceive and act toward new, foreign residents. Everyday interactions with citizens greatly influence the desire to settle in a city and promote feelings of home, or they can push refugees into ethnic enclaves within a particular city or country.

\section{Refugees and Other Movers}


Migration studies and migration discourse generally have long separated refugees from other types of movers, distinguishing the two based on assumptions about the degree of choice involved in the decision to move. Indeed, refugees have been excluded from general migration discourse since they were first recognized as a conceptually distinct social category at the end of World War II. Nevertheless, refugees are not unlike other types of migrants. Migration is about finding security and working toward the best interests of individuals and households. Moving in search of security, be it physical, social, or economic, compels people to make decisions about where they can go in search of opportunities. In this way, refugees are no different from others who migrate. Differences lie in the ability or perceived ability to feel or be secure. Forced migration is often used interchangeably with refugee migration, implying there are few or limited choices to be made, but several cases provide examples of people who use an opportunity such as violence to move and others - Syrians, for example - who will not. Cultures of migration (Cohen \& Sirkeci, 2011) apply to refugees just as much as they do to economic migrants.

Like other migrants, refugees are situated in the wider socio-cultural context of the host society, but are also embedded in complex social networks. For example, Somalis started moving to South Africa when Nelson Mandela was elected president in 1994. Migration accelerated with the passage of the South Africa Refugee Rights Act of 1998. The Act granted asylum seekers entry into South Africa and the right to apply for refugee status. The different life experiences of movers - and perhaps even their motivations for moving - have had, over time, a profound effect on the Somalis living in South Africa. Somali refugees who fled their homes 25 years ago are distinguished from those who left East Africa five years ago. Those early movers are better integrated into South African society; they arrived before antiimmigrant sentiment inspired waves of xenophobic violence across the country; and they had access to and seized different economic opportunities. These differences often defined and granted early movers more powerful positions within their communities and broader social networks. More recent arrivals to South Africa carry the baggage of displacement and decades of violence in Somalia as well as a cultural restructuring of Somali identity that included a more conservative interpretation (and practice) of Islam. As clusters of Somali communities have grown in the country, so too has their visibility as foreigners and the perception that they are economic threats to citizens living in the cities and townships where Somali traders and entrepreneurs work.

For many movers, migration is an issue of security, and movement is tied largely to a search for new opportunities to innovate, participate, contribute, and develop themselves. In the case of Somalis, physical and/or economic insecurity led them to South Africa, and those same insecurities compelled 
many to continue their journeys elsewhere to places where they can feel safe from structural and xenophobic violence and free to explore economic opportunities. While circumstances shape refugee journeys, which we cover in the next section, culture and social connections play a key role in determining where and why refugees move in temporary settlement spaces or after arriving in final destination resettlement countries. Somali communities grew in South Africa through social networks and chain migration. Those who planned to stay temporarily may have decided to remain in the country and vice-versa.

Like other migrants, refugees often depend on their ethnic communities for practical and emotional support. For example, a growing number of refugees living in the UK were dispersed across the country on a no-choice basis after applying for asylum. The UK's dispersal policy was implemented in 2000 under the 1999 Immigration and Asylum Act, a national policy aimed at spreading the 'burden' of housing asylum seekers across the country. Whether those individuals stayed in their dispersal locations or moved on once they received their refugee status is tied to several factors, including cultural traditions, ethnicities, and practical needs such as employment. In our research, we found that Eritrean refugees are especially mobile as they tap into their social networks for assistance finding jobs. This is a common theme of most refugees who were dispersed to smaller cities but subsequently migrate away from those locations. The desire to move to a larger city (such as Manchester or London) due to the presence of social networks as well as employment opportunities was also observed among Iranians, who similarly appear to be relatively mobile (Stewart \& Shaffer, 2015). It is not only the existence of ethnic communities that are important for attracting refugees as they relocate, but that the ethnic communities they seek play a key role in obtaining employment (Cheung \& Phillimore, 2014; Stewart \& Shaffer, 2015).

Refugees from countries such as Eritrea and Somalia tend to have lower levels of English proficiency and fewer qualifications on arrival to the UK and are more likely to need assistance in finding employment (Cebulla, Daniel \& Zurawan, 2010). Moving onward is a primary way to access support provided by their ethnic communities. Members of those communities often help with securing jobs and providing the tools that lead to integration. Conversely, good English skills may decrease the tendency to migrate toward ethnic communities due to self-sufficiency, a factor which we will explore among Zimbabweans later. Overall, these patterns of movement are not dissimilar to chain migration flows that have been observed at the national scale and documented extensively within the field of migration studies. For example, key motivations for migrating, which include moving for employment opportunities, joining 
family members, and moving toward pre-existing ethnic communities, are findings that resonate with existing knowledge on immigrants' and ethnic minority populations' internal migration (Kritz \& Nogle, 1994; Zavodny, 1999). The culture of migration evident among refugees is strong evidence for thinking about patterns of internal refugee flows alongside other types of migration.

\section{Migration Trajectories}

Migration discourse among politicians and in the news generally would have us believe that all movers have clear, well-defined end points in mind when they begin their sojourns. While many migrants may have a planned route and an ideal destination as their goal, just as many movers are looking for security and a place - any place - that provides them with an opportunity to call it home. Sometimes the first stop on a migration journey is or becomes the destination; other times it is simply a place to pause before moving on. Sometimes a perceived destination changes, before or after it has been reached by a refugee (Shaffer, Ferrato \& Jinnah, 2018). Cultural attitudes within receiving societies, in tandem with immigration policies, initial assistance from the host, and the socioeconomic climate, can alter perceptions of a (re)settlement destination and make it more or less appealing as a place to call home (Kibreab, 2004). Each of these components influence household outcomes, sociocultural arrangements, and onward migration and resettlement decisions. These same conditions may impel refugees to continue moving within or beyond a country's borders.

Conventional wisdom has it that refugees should move to a country neighboring their homeland. Indeed, objections to refugee resettlement globally include questioning why individuals cannot simply go somewhere closer to home. The reality is that the majority of the world's refugees either are internally displaced or hosted in neighboring, less developed countries. The UNHCR estimates that about 80 percent of refugees live in countries neighboring their countries of origin. For example, the top refugee-hosting countries are currently Turkey (3.7 million), Pakistan (1.4 million), Uganda (1.2 million), Sudan (1.1 million), and Germany (1.1 million) (UNHCR, 2019a). Except for Germany, the top refugee destinations are in less developed countries that are geographically proximate to refugee source countries. Nevertheless, there are several reasons why the UNHCR 'spreads the burden' of resettlement to global destinations or why refugees seize opportunities to travel further afield. From a refugee resettlement standpoint, logistically and practically, it is not possible for a single or even multiple neighboring countries to absorb and support thousands or millions of fleeing refugees crossing borders when a crisis warrants mass migration. There is a lack of social and financial resources in most potential 
destination countries, including housing, food, jobs, support, hospitals, schools, and so on to manage high volumes of movers. While remaining in temporary accommodations in those countries may expedite resettlement elsewhere, many migrants will continue their journey independently in the hopes of finding a new home.

About one-quarter of the world's refugees are living in sub-Saharan Africa. Conflicts in Somalia, South Sudan, Democratic Republic of the Congo, Burundi, and other countries have led to internal displacement and refugee crises across the continent. Urban centers and refugee camps in neighboring countries, as well as cities in South Africa (where there are no camps) and the Mediterranean Coast of North Africa, have become destinations for refugees who are motivated to continue their journey or wish to wait for conflicts to be resolved so they can return to their home communities and rebuild their lives. Onward migration to Europe and North America is limited due to increasingly restrictive immigration policies, not to mention the exorbitant costs and logistical challenges associated with reaching those countries in the absence of legal trajectories. Moreover, individuals desperate to reach the shores of Europe face a perilous journey and often face tragic consequences. For these reasons, many refugees stay close to home. Referring to the Somali example again, they and other refugee groups have been enticed by the relative ease of reaching South Africa and the promise of legal refugee status once they arrive - a contrast from other African countries that do not offer settlement or legal recognition to asylum seekers, leaving them vulnerable to detention. South Africa offers refugees critically important economic opportunities for business entrepreneurs hoping to earn enough profit to provide for their families locally and abroad, making the country irresistible to those weary of instability at home, limited opportunities in other parts of Africa, and desperate for legal status (Crush et al, 2017; Jinnah, 2010; Sadouni, 2009; Shaffer, 2018).

The degree of cultural (dis)similarity between refugees and their hosts is one significant factor influencing migration outcomes (Kibreab, 2004). Certainly, the cultural context of migration flows is crucial in shaping mobility patterns at the sub-national level. In the UK, refugees often experience their first encounters with racism in dispersal or temporary accommodation, shaping their perception of the cities and influencing onward migration decisions. In our research, we found that children and youths perpetrate racist behaviors in schools, parks, and toward residents in their neighborhoods, which can influence onward migration decisions (Stewart \& Shaffer, 2015). Racist behaviors are prevalent on local buses (from bus drivers and passengers), resulting in refugees feeling unwelcome. Three different Somali women living in Glasgow recounted how bus drivers were standoffish and often passed them by 
without stopping, despite their request to board the bus. The women also spoke of negative attitudes and the racist language used by fellow bus passengers toward them. While some refugees accept this as part of living in the UK, others do not feel welcome and act to move to neighborhoods or cities that they perceive as more diverse and multi-cultural. In post 9/11 Britain, Muslim refugees face double discrimination as they live with the label 'refugee' as well as their religious identity. This tension drives refugees to situate themselves within their ethnic or religious communities or relocate to different cities in the country that they perceive are more diverse and hospitable. This also can lead to onward migration to other countries within the EU or further afield.

By contrast, other refugee groups have not felt isolated in resettlement due to cultural dissimilarities with their hosts. Zimbabweans in the UK have generally preferred to integrate in their dispersal locations and have not migrated toward other Zimbabweans. Zimbabweans tend to be highly skilled, hold educational qualifications, and are fluent in English (Bloch, 2006), making them more independent and less reliant on existing ethnic communities. Interestingly, many view such independence from coethnic communities as an important step toward successful integration in UK society (Stewart \& Shaffer, 2015). These outcomes can be explained by, and traced to, historical connections, education, English language, and previous knowledge of the UK. The legacy of colonialism has influenced recent refugee experiences in the country. With a lack of Zimbabwean communities and organizations, there is a tendency for refugees to view the challenges of adaptation as an individual rather than a collective responsibility. Additionally, many Zimbabweans entered the UK legally as visitors or students and later claimed asylum when they were unable to return home (Pasura, 2013). This means that many Zimbabweans live for considerable time in the UK before claiming asylum and being dispersed following UK policy. Along with close ties to Britain through friends and relatives, this provides them with extensive knowledge about the UK system and locations around the country, perhaps leaving them better placed to make informed decisions about where to move.

\section{Resettlement and the Perception of Permanence}

It is assumed that refugees who are accepted for resettlement in a third country or who are granted asylum will see the security in having legalized, permanent status as synonymous with halting migration, ending the journey, and finding a contentedness in a new home. But literature on mixed migration intentions and motivations of migrant and refugee groups would intuitively suggest the opposite. The reality for many refugees is a lack of permanence and the tendency to keep on moving either internally 
or internationally. Having been uprooted from 'home', for some movers there is a continual striving to settle and find a better home. This can be a long process involving years of movement and resettlement. In this section, therefore, we challenge the sedentary bias of settlement policies by shining a light on the culture of migration among refugee populations.

Many countries have implemented dispersal policies to control the resettlement of refugees within their borders. Several European countries have introduced these policies to 'spread the burden' of housing refugee populations such as Sweden, the Netherlands, and Denmark. Like the UK, these systems are primarily housing-led with less focus on long-term integration issues. Onward migration studies have identified key reasons for moving after dispersal, including employment gains, family reunification, and the desire to live within co-ethnic communities, although the importance of factors can vary for different nationality groups. The classic UK study of Vietnamese resettlement found that half of the dispersed refugees moved onward to London, Birmingham, and Manchester to join existing Vietnamese communities (Robinson \& Hale, 1989). EU citizenship and freedom of movement also means refugees can choose to live and work in any European country, such as Somalis who have permanently relocated to the UK after dispersal in the Netherlands (van Liempt, 2011). Likewise, as part of refugees' adjustment in new societies, resettled refugees in the US, Canada, and Australia have moved internally from rural and urban locations to gain social and emotional support, as well as for economic reasons (Harte, Childs \& Hastings, 2011; Newbold, 2007; Simich, Beiser \& Mawani, 2002).

Pre-existing ethnic communities provide new refugees with material, financial, and emotional assistance that is critical to long-term settlement. Refugees locate in ethnic clusters in order to provide mutual support and integration assistance. Being settled in locations with no pre-existing ethnic community can cause refugees to feel isolated, lonely, and vulnerable to racist abuse. Harassment often provides the impetus to onward migrate toward family members and ethnic communities (Robinson, Andersson \& Musterd, 2003). For example, Somalis in the Netherlands have regrouped and moved to large Dutch cities as well as across Europe for employment, for educational opportunities, and to join existing communities of co-nationals (van Liempt, 2011). Resettled refugees in Canada also have been found to relocate and move toward ethnic communities to overcome a sense of isolation and language barriers. Secondary migration is prompted by a desire to reconstitute family and social support networks to ensure emotional and material stability (Simich, Beiser \& Mawani, 2002), factors that are essential for integration. 
'Integration' has become a buzzword for governments addressing the issues refugees face in their countries, such as making a life in a foreign land with markedly different social, cultural, and economic realities than their hosts. There is extensive debate over what is meant by integration (Castles et al, 2002), but in refugee studies key work has examined structural integration and acculturation, with Ager and Strang's (2008) seminal work identifying a conceptual framework for refugee integration. The challenge for refugees is in adapting to ideological and sometimes religious differences as well as in learning languages and navigating new ways of managing daily life. States increasingly perceive cultural dissimilarities as problematic, as something that requires a solution and not as diversity worthy of celebration (Dempster \& Hargrave, 2017; Esses, Hamilton \& Gaucher, 2017). We argue that integration is closely linked to mobility and helps to explain why some refugees migrate to pre-existing ethnic communities.

What does this mean for refugee resettlement and the permanence of a destination country? Migration is a fluid process and culture influences the ways in which individuals conceive, plan, and execute their journeys. Cultural knowledge can drive refugee strategies for building a life in resettlement spaces or moving on when realities fall short of expectations. Individuals lacking these tools often lean on their coethnic communities for support to survive in their new surroundings. Those who are equipped with assets that align them with their hosts may find it easier to settle in a new space. Perceptions that a receiving society has of ethnic groups may determine the treatment and services refugees receive from their hosts. These relationships are as varied as the individuals who experience them. Resettlement dreams may involve global locations, but in practice there are several moving parts that guide where individuals go, how they get there, and the interactions that result from those decisions. Culture may influence those experiences and drive individual refugees to feel content in their new home or to continue searching. It is a critically important piece to understanding insecurity, the nature of mobility, and the complexity of human relationships.

\section{References}

Ager, A. \& Strang, A. (2008) Understanding Integration: A Conceptual Framework. Journal of Refugee Studies. 21(2), 166-191.

Betts, A. (2013) Survival Migration: Failed Governance and the Crisis of Displacement. New York, Cornell University Press. 
Bloch, A. (2006) Emigration from Zimbabwe: Migrant Perspectives. Social Policy and Administration. 40(1), 67-87.

Cabot, H. (2016) "Refugee Voices": Tragedy, Ghosts, and the Anthropology of Not Knowing. Journal of Contemporary Ethnography. 45(6), 645-672.

Castles, S., Korac, M., Vasta, E. \& Vertovec, S. (2002) Integration: Mapping the Field. Home Office Online Report 29/03. London, Home Office.

Cebulla, A., Daniel, M. \& Zurawan, A. (2010) Spotlight on Refugee Integration: Findings from the Survey of New Refugees in the United Kingdom. Research Report 37. London, Home Office.

Cheung, S. Y. \& Phillimore, J. (2014) Refugees, social capital, and labour market integration in the UK. Sociology. 48(3), 518-536.

Cohen, J. \& Sirkeci, I. (2011) Cultures of Migration. Austin, University of Texas Press.

Crawley, H. \& Skleparis, D. (2018) Refugees, migrants, neither, both: categorical fetishism and the politics of bounding in Europe's 'migration crisis'. Journal of Ethnic and Migration Studies. 44(1), 48-64.

Crush, J., Tawodzera, G., McCordic, C. \& Ramachandran, S. (2017) Refugee Entrepreneurial Economies in Urban South Africa. Southern African Migration Programme (SAMP) Policy Series No. 76. Ontario, Canada, SAMP.

Dempster, H. \& Hargrave, K. (2017) Understanding public attitudes towards refugees and migrants. Working paper 512. London, Overseas Development Institute.

Esses, V. M., Medianu, S. \& Lawson, A. S. (2013) Uncertainty, Threat, and the Role of the Media in Promoting the Dehumanization of Immigrants and Refugees. Journal of Social Issues. 69(3), 518-536.

Esses, V. M., Hamilton, L. K. \& Gaucher, D. (2017) The Global Refugee Crisis: Empirical Evidence and Policy Implications for Improving Public Attitudes and Facilitating Refugee Resettlement. Social Issues and Policy Review. 11(1), 78-123. 
FitzGerald, D. S. \& Arar, R. (2018) The Sociology of Refugee Migration. Annual Review of Sociology. 44, 387-406.

Harte, W., Childs, I. R. W. \& Hastings, P. A. (2011) African Refugee Communities in Southeast Queensland: forces of concentration and dispersion. Australian Geographer. 42(3), 325-342.

Jinnah, Z. (2010) Making Home in a Hostile Land: Understanding Somali Identity, Integration, Livelihood and Risks in Johannesburg. Journal of Sociology and Social Anthropology. 1(1-2), 91-99.

Johnson, H. L. (2011) Click to Donate: visual images, constructing victims and imagining the female refugee. Third World Quarterly. 32(6), 1015-1037.

Kibreab, G. (2004) Refugeehood, Loss and Social Change: Eritrean Refugees and Returnees. In: Essed, P., Frerks, G. \& Schrijvers, J. (eds.) Refugees and the Transformation of Societies: Agency, Policies, Ethics and Politics. New York and Oxford, Berghahn Books, pp. 19-30.

Kritz, M. M. \& Nogle, J. M. (1994) Nativity concentration and internal migration among the foreign-born. Demography. 31(3), 509-524.

Murray, K. E. \& Marx, D. M. (2013) Attitudes Toward Unauthorized Immigrants, Authorized Immigrants, and Refugees. Cultural Diversity and Ethnic Minority Psychology. 19(3), 332-341.

Newbold, B. (2007) Secondary migration of immigrants to Canada: an analysis of LSIC wave 1 data. The Canadian Geographer. 51(1), 58-71.

Office of Immigration Statistics (2019) Annual Flow Report, Refugees and Asylees: 2017. Washington, DC, Department of Homeland Security (DHS).

Ongenaert, D. \& Joye, S. (2019) Selling displaced people? A multi-method study of the public communication strategies of international refugee organisations. Disasters. 43(3), 478-508.

Pasura, D. (2013) Modes of incorporation and transnational Zimbabwean migration to Britain. Ethnic and Racial Studies. 36(1), 199-218. 
Robinson, D. (2010) The neighbourhood effects of new immigration. Environment and Planning A. 42, 2451-2466.

Robinson, V. \& Hale, S. (1989) The geography of Vietnamese secondary migration in the UK. ESRC Research Paper in Ethnic Relations. 10, 1-51.

Robinson, V., Andersson, R. \& Musterd, S. (2003) Spreading the Burden? European Policies to Disperse Asylum Seekers. Bristol, Policy Press.

Sadouni, S. (2009) 'God is not Unemployed': Journeys of Somali Refugees in Johannesburg. African Studies. 68(2), 235-249.

Shaffer, M. (2018) Social Control in Transnational Families: Somali Women and Dignity in Johannesburg. In: Hiralal, K. \& Jinnah, Z. (eds.) Gender and Mobility in Africa: Borders, Bodies and Boundaries. Cham, Switzerland, Palgrave Macmillan, pp. 223-249.

Shaffer, M., Ferrato, G. \& Jinnah, Z. (2018) Routes, Locations, and Social Imaginary: A Comparative Study of the On-Going Production of Geographies in Somali Forced Migration. African Geographical Review. 37(2), 159-171.

Simich, L., Beiser, M. \& Mawani, F. (2002) Paved with good intentions: Canada's refugee destining policy and paths of secondary migration. Canadian Public Policy. 28(4), 597-607.

Stewart, E. \& Shaffer, M. (2015) Moving On? Dispersal Policy, Onward Migration and Integration of Refugees in the UK. Glasgow, University of Strathclyde.

UNHCR (2019a) Figures at a Glance. Available from: https://www.unhcr.org/uk/figures-at-a-glance.html [Accessed 22 ${ }^{\text {nd }}$ January 2020].

UNHCR (2019b) Global Trends: Forced Displacement in 2018. Geneva, UNHCR.

van Liempt, I. (2011) From Dutch dispersal to ethnic enclaves in the UK: the relationship between segregation and integration examined through the eyes of Somalis. Urban Studies. 48(16), 3385-3398. 
White House (2019) Presidential Determination on Refugee Admissions for Fiscal Year 2020. Available from: https://www.whitehouse.gov/presidential-actions/presidential-determination-refugeeadmissions-fiscal-year-2020/ [Dated $1^{\text {st }}$ November 2019].

Zavodny, M. (1999) Determinants of recent immigrants' locational choices. International Migration. 33(4), 1014-1030.

Zetter, R. (2007) More labels, fewer refugees: remaking the refugee label in an era of globalization. Journal of Refugee Studies. 20(2), 172-192. 